LC 1120

Supersedes LC 1056
Actions at the 1979 General Conference on Weights and Measures (CGPM)*

Since the last publication of the NBS guidelines for the use of the International System of Units (SI) in 1977, thre: important actions concerning SI have been taken by the General Conference on Weights and Measures. This revised version of the NBS guidelines reflects these decisions.

At their meeting in Paris, France, October 8-12, 1979, the General Conference:

(1) Redefined the base SI unit candela to readThe candela is the luminous intensity, in a given direction, of a source that emits monochromatic radiation of frequency 540 $\times 10^{12}$ hertz and of which the radiant intensity in that direction is $1 / 683$ watt per steradian.

(2) Adopted the special name sievert, symbol Sv, for the SI unit of dose equivalent in the field of radiological protection. The sievert is equal to one joule per kilogram.

(3) Adopted I and $\mathrm{L}$ as alternative symbols for the unit liter.

\section{Guidelines for Use of the}

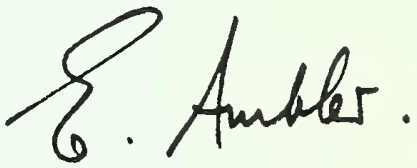

Ernest Ambler

\section{Director}

* E. Ambler was the U.S. delegate to the CCPM, accompanied by advisors Francis $X$. Cunningham (Department of State), Edward L. Brady (NBS), and Abraham S. Friedman (American Embassy, Paris).

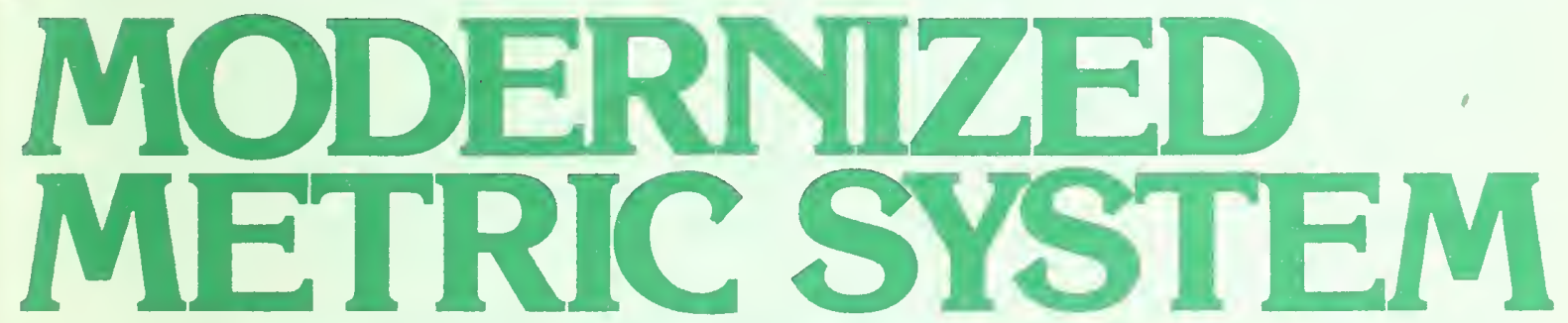

The International System of Units

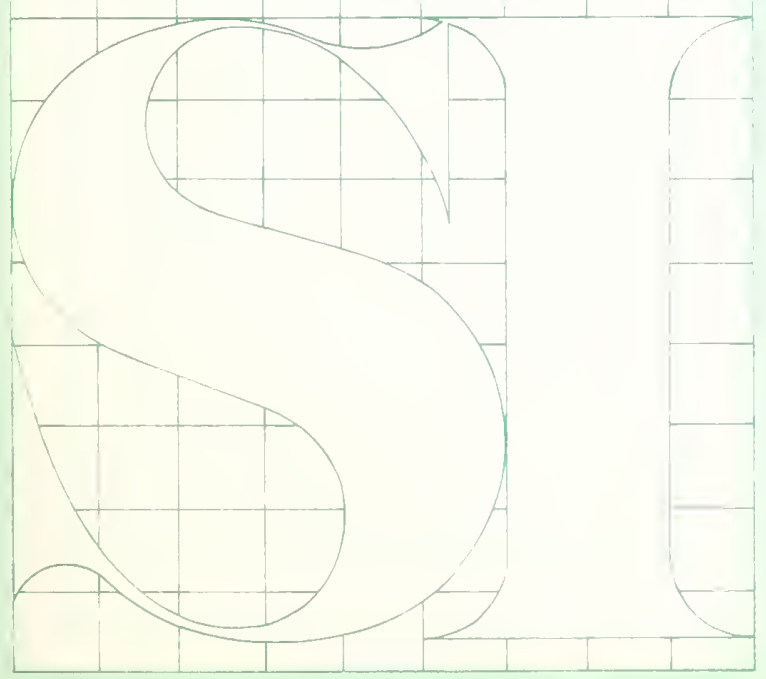

\section{$\mathrm{T}$}

HE following Guidelines have been adopted by the National Bureau of Standards of the U.S. Department of Commerce for use of the International System of Units $(S I),{ }^{1}$ informally called the metric system.

These Guidelines ${ }^{2}$ reflect the decisions of the General Conference on Weights and Measures (CGPM) and its subordinate Committees which defined the modernized metric system and gave offi-

1 The International System of Units (SI) was initially defined and given official status by the 11 th General Conference on Weights and Measures, 1960. A complete listing of the SI units is presented in NBS Special Publication 330, 1977 Edition. A summary of the $S 1$ is given in Appendix 1 of this document.

${ }^{2}$ These Guidelines supersede LC 1056 dated November 1977 and those that appeared in DIMENSIONS/NBS, October 1977. 
cial status to SI in 1960. The United States holds a place on these international bodies by virtue of its adherence to the Treaty of the Meter, signed in 1875. The National Bureau of Standards acts as the official U.S. representative to the various international bodies formed by the Treaty.

The National Bureau of Standards, in light of the Metric Conversion Act of 1975, recommends the use of metric units except in contexts where the exclusive use of metric units would needlessly confuse the intended audience. In these cases, the dual use of metric and inch-pound (customary) units may serve the two purposes of not only communicating the contents but also familiarizing the readers with the new metric system.

In all cases, NBS recommends a common-sense approach to metric conversion. These Guidelines are meant to provide NBS recommendations on the use of the modernized metric system while recognizing the evolving nature of metric practice in the U.S.

For further information concerning metric conversion in the United States, the reader should contact the U.S. Metric Board, 1815 N. Lynn Street, Suite 600, Arlington, VA 22209. For further information about the metric system, contact the NBS Office of Technical Publications, Washington, D.C. 20234.

\section{The Metric System: SI}

The $\mathrm{SI}$ is constructed from seven base units for independent quantities plus two supplementary units for plane angle and solid angle. (See table 1). Units for all other quantities are derived from these nine units. In table 2 are listed 19 SI derived units with special names. These units are derived from the base and supplementary units in a coherent manner, which means they are expressed as products and quotients of the nine base and supplementary units without numerical factors. All other SI derived units, such as those in tables 3 and 4 , are similarly derived in a coherent manner from the 28 base, supplementary, and special-name SI units. For use with the SI units, there is a set of 16 prefixes (see table 5) to form multiples and submultiples of these units. For mass, the prefixes are to be applied to the gram instead of to the SI base unit, the kilogram.

The SI units together with the SI prefixes provide a logical and interconnected framework for measurements in science, industry, and commerce. NBS encourages the use of SI in the United States.

\section{Fundamental Constants/Natural Units}

In some cases, quantities are commonly expressed in terms of fundamental constants of nature, and use of these constants or "natural units" is acceptable. The author, however, should state clearly which natural units are being used; such broad terms as "atomic units" should be avoided when there is danger of confusion.

Typical examples of natural units are:

\begin{tabular}{ll}
\multicolumn{1}{c}{ Unit } & Symbol \\
\hline elementary charge & $\mathrm{e}$ \\
electron mass & $m_{\mathrm{e}}$ \\
proton mass & $m_{\mathrm{p}}$ \\
Bohr radius & $\mathrm{a}_{\mathrm{o}}$ \\
electron radius & $r_{\mathrm{e}}$ \\
Compton wavelength of electron & $\lambda_{\mathrm{C}}$ \\
Bohr magneton & $\mu_{\mathrm{B}}$ \\
nuclear magneton & $\mu_{\mathrm{N}}$ \\
speed of light & $\mathrm{c}$ \\
Planck constant & $h$
\end{tabular}

\section{Units Acceptable for Use with SI}

Certain units which are not part of the SI are used so widely that it is impractical to abandon them. The units that are accepted for continued use with the International System are listed in table 6 . It is likewise necessary to recognize, outside the International System, the following units which are used in specialized fields:

Unit

electron volt

unified atomic mass unit astronomical unit parsec

The units shown with an asterisk in table 7 are used in limited fields and have been authorized by the International Committee for Weights and Measures (CIPM), the international committee that guides the technical work of the Treaty of the Meter, for temporary use in those fields.

The short names for compound units (such as "coulomb" for "ampere second" and "pascal" for "newton per square meter") exist for convenience, and either form is correct (see table 2). For example, communication sometimes is facilitated if the author expresses magnetic flux in the compound terr volt seconds (instead of using the synonym, webe. because of the descriptive value implicit in the compound phrase. 


\section{Special Considerations}

The kelvin (K) is the SI base unit of temperature; this unit is properly used for expressing temperature and temperature intervals. However, wide use is also made of the degree Celsius $\left({ }^{\circ} \mathrm{C}\right)$ for expressing temperature and temperature intervals. The Celsius scale (formerly called centigrade) is related directly to thermodynamic temperature (kelvins) as follows:

The temperature interval one degree Celsius equals one kelvin exactly.

Celsius temperature $(t)$ is related to thermodynamic temperature $(T)$ by the equation:

$$
t=T-T_{0}
$$

where $T_{0}=273.15 \mathrm{~K}$ by definition.

Words and symbols should not be mixed. If mathematical operations are indicated, for example, only symbols should be used. Any of the forms "joules per mole," "J/mol," "J"mol"-1" is considered good usage, but the forms "joules/mole" and "joules"mol" "1" $^{-1}$ are not. See Appendix 2 for additional rules.

Logarithmic measures such as $\mathrm{pH}, \mathrm{dB}$ (decibel), and $\mathrm{Np}$ (neper) are acceptable.

Over the years the term weight has been used to designate two quantities: mass and force. NBS supports the recommendation in the American $\mathrm{Na}$ tional Standard for Metric Practice quoted in Appendix 3 , that the term weight should be avoided

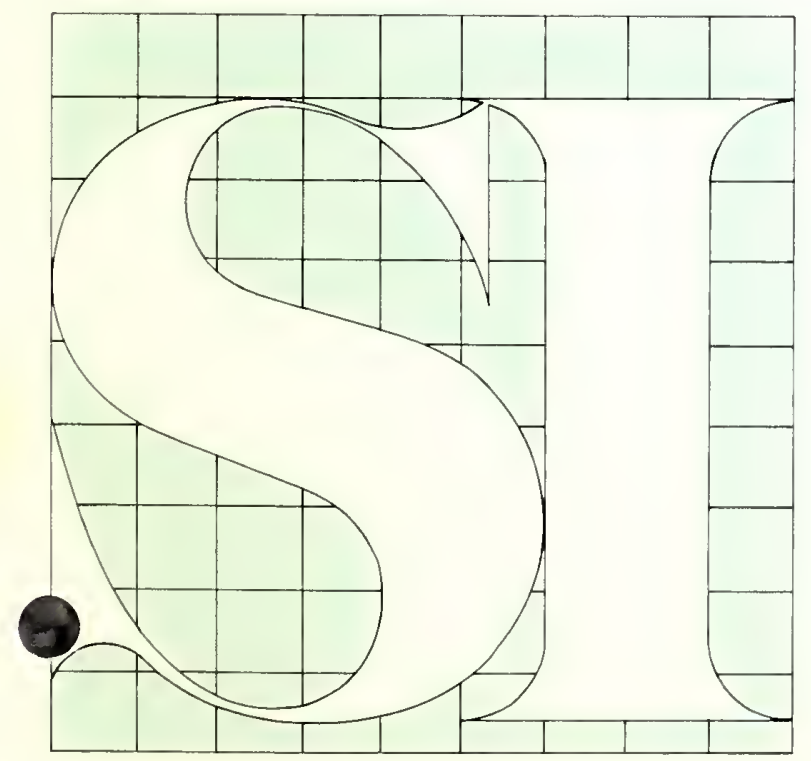

in technical publicatrons except under circumstances in which its meaning is completely clear.

It is also recommended that the terms atomic weight and molecular weight be replaced by relative atomic mass and relative molecular mass in accordance with established international practice. ${ }^{3}$

\section{Descriptive and Essential Data}

Descriptive data describe arrangements, environments, noncritical dimensions and shapes of apparatus, and similar measurements not affecting calculations or results. Such data should be expressed in SI units unless this makes the expression excessively complicated. For example, commercial gauge designations, commonly used items identified by nominal dimensions, or other commercial nomenclatures (such as drill sizes, or standards for weights and measures) expressed in inch-pound units are acceptable.

Essential data express or interpret the quantitative results being reported. All such data shall be expressed solely in SI units except in those fields where (a) the sole use of SI units would create a serious impediment to communications, or (b) $\mathrm{SI}$ units have not been specified. Exceptions may also occur when dealing with commercial devices, standards, or units having some legal definition, such as commercial weights and measures. Even in such instances, SI units should be used when practical and meaningful; for example, this may be done by adding non-SI units in parentheses after SI units. In tables, SI and inch-pound units may be shown in parallel columns. If coordinate markings in non-S! units are included in graphs, they should be displayed on the top and right-hand sides of the figure.

\section{Additional References}

For additional information on the use of SI units, the reader is directed to the following publications:

NBS SP 330, 1977 Edition, "The International System of Units: SI," the translation of the official text, "Le Système International d'Unités," (1977).

ISO International Standard 1000 (1973 Edition) "SI Units and Recommendations for L'se of Their Multiples."

American National Standard Z210.1-1976, American Standard for Metric Practice.

Examples of conversion factors from non-SI units to $\mathrm{SI}$ are provided in table 7 .

${ }^{3} 15031 / \mathrm{VII}$ "Quantities and Units of Physical Chemistry and Molecular Physics." 
TABLE 1. SI base and supplementary units

\section{Units and Conversion Factors}

\begin{tabular}{|c|c|c|c|}
\hline & Quantity $^{*}$ & $\begin{array}{l}\text { Unit } \\
\text { Name }\end{array}$ & $\begin{array}{c}\text { Unit } \\
\text { Symbol }\end{array}$ \\
\hline & length & meter & $\mathrm{m}$ \\
\hline & mass $^{1}$ & kilogram & $\mathrm{kg}$ \\
\hline \multirow[t]{5}{*}{ SI base units } & time & second & $\mathrm{s}$ \\
\hline & eiectric current & ampere & A \\
\hline & thermodynamic temperature & kelvin & K \\
\hline & amount of substance & mole & mol \\
\hline & iuminous intensity & candela & $\mathrm{cd}$ \\
\hline \multirow[t]{2}{*}{ SI supplementary units } & plane angle & radian & $\mathrm{rad}$ \\
\hline & solid angle & steradian & sr \\
\hline
\end{tabular}

'See Appendix 3 for a discussion of the terms "mass" and "weight."

"Quantity here and in Tables 2, 3, 4, and 7 means a measurable attribute.

TABLE 2. SI derived units with special names

\begin{tabular}{|c|c|c|c|c|}
\hline \multirow[b]{2}{*}{ Quantity } & \multicolumn{4}{|c|}{ SI Unit } \\
\hline & Name & Symbol & $\begin{array}{l}\text { Expression } \\
\text { in terms } \\
\text { of other } \\
\text { units }\end{array}$ & $\begin{array}{l}\text { Expression } \\
\text { in terms } \\
\text { of SI base } \\
\text { units }\end{array}$ \\
\hline frequency & hertz & $\mathrm{Hz}$ & & $\mathrm{S}^{-1}$ \\
\hline force & newton & $\mathrm{N}$ & & $\mathrm{m} \cdot \mathrm{kg} \cdot \mathrm{s}^{-2}$ \\
\hline pressure, stress & pascal & $\mathrm{Pa}$ & $\mathrm{N} / \mathrm{m}^{2}$ & $\mathrm{~m}^{-1} \cdot \mathrm{kg} \cdot \mathrm{s}^{-2}$ \\
\hline energy, work, quantity of heat & joule & $J$ & $\mathrm{~N} \cdot \mathrm{m}$ & $\mathrm{m}^{2} \cdot \mathrm{kg} \cdot \mathrm{s}^{-2}$ \\
\hline power, radiant flux & watt & W & $\mathrm{J} / \mathrm{s}$ & $\mathrm{m}^{2} \cdot \mathrm{kg} \cdot \mathrm{s}^{-3}$ \\
\hline quantity of electricity, electric charge & coulomb & $\mathrm{C}$ & $A \cdot S$ & $s \cdot A$ \\
\hline $\begin{array}{l}\text { electric potential, } \\
\text { potential difference, electromotive force }\end{array}$ & volt & V & W/A & $\mathrm{m}^{2} \cdot \mathrm{kg} \cdot \mathrm{s}^{-3} \cdot \mathrm{A}^{-1}$ \\
\hline capacitance & farad & $\mathrm{F}$ & $\mathrm{C} / \mathrm{V}$ & $\mathrm{m}^{-2} \cdot \mathrm{kg}^{-1} \cdot \mathrm{s}^{4} \cdot \mathrm{A}^{2}$ \\
\hline electric resistance & ohm & $\Omega$ & $V / A$ & $\mathrm{~m}^{2} \cdot \mathrm{kg} \cdot \mathrm{s}^{-3} \cdot \mathrm{A}^{-2}$ \\
\hline conductance & siemens & $\mathrm{S}$ & $A / V$ & $\mathrm{~m}^{-2} \cdot \mathrm{kg}^{-1} \cdot \mathrm{s}^{3} \cdot \mathrm{A}^{2}$ \\
\hline magnetic flux & weber & $\mathrm{Wb}$ & $V \cdot s$ & $\mathrm{~m}^{2} \cdot \mathrm{kg} \cdot \mathrm{s}^{-2} \cdot \mathrm{A}^{-1}$ \\
\hline magnetic flux density & tesla & $\mathrm{T}$ & $\mathrm{Wb} / \mathrm{m}^{2}$ & $\mathrm{~kg} \cdot \mathrm{s}^{-2} \cdot \mathrm{A}^{-1}$ \\
\hline inductance & henry & $\mathrm{H}$ & $\mathrm{Wb} / \mathrm{A}$ & $m^{2} \cdot k g \cdot s^{-2} \cdot A^{-2}$ \\
\hline Celsius temperature $^{(a)}$ & degree Celsius & ${ }^{\circ} \mathrm{C}$ & & $\mathrm{K}$ \\
\hline luminous flux & lumen & $\operatorname{lm}$ & & $\mathrm{cd} \cdot \mathrm{sr}^{(b)}$ \\
\hline illuminance & lux & Ix & $\mathrm{Im} / \mathrm{m}^{2}$ & $m^{-2} \cdot c d \cdot s r^{(b)}$ \\
\hline activity (of a radionuclide) & becquerel & $\mathrm{Bq}$ & & $\mathrm{s}^{-1}$ \\
\hline $\begin{array}{l}\text { absorbed dose, specific } \\
\text { energy imparted, kerma, } \\
\text { absorbed dose index }\end{array}$ & gray & Gy & $\mathrm{J} / \mathrm{kg}$ & $\mathrm{m}^{2} \cdot \mathrm{s}^{-2}$ \\
\hline $\begin{array}{l}\text { dose equivalent, dose } \\
\text { equivalent index }\end{array}$ & sievert & Sv & $\mathrm{J} / \mathrm{kg}$ & $\mathrm{m}^{2} \cdot \mathrm{s}^{-2}$ \\
\hline
\end{tabular}

(a) See Special Considerations, p.15

(b) In this expression the steradian (sr) is treated as a base unit. 
TABLE 3. Some SI derived units expressed in terms of base units

\begin{tabular}{|c|c|c|}
\hline Quantity & SI Unit & $\begin{array}{l}\text { Unit } \\
\text { Symbol }\end{array}$ \\
\hline area & square meter & $\mathrm{m}^{2}$ \\
\hline volume & cubic meter & $\mathrm{m}^{3}$ \\
\hline speed, velocity & meter per second & $\mathrm{m} / \mathrm{s}$ \\
\hline acceleration & meter per second squared & $\mathrm{m} / \mathrm{s}^{2}$ \\
\hline wave number & 1 per meter & $\mathrm{m}^{-1}$ \\
\hline density, mass density & kilogram per cubic meter & $\mathrm{kg} / \mathrm{m}^{3}$ \\
\hline current density & ampere per square meter & $\mathrm{A} / \mathrm{m}^{2}$ \\
\hline magnetic field strength & ampere per meter & $\mathrm{A} / \mathrm{m}$ \\
\hline $\begin{array}{l}\text { concentration (of amount } \\
\text { of substance) }\end{array}$ & mole per cubic meter & $\mathrm{mol} / \mathrm{m}^{3}$ \\
\hline specific volume & cubic meter per kilogram & $\mathrm{m}^{3} / \mathrm{kg}$ \\
\hline luminance & candela per square meter & $\mathrm{cd} / \mathrm{m}^{2}$ \\
\hline
\end{tabular}

TABLE 4. Some SI derived units expressed by means of special names

SI Unit

\begin{tabular}{|c|c|c|c|}
\hline Quantity & Name & Symbol & $\begin{array}{l}\text { Expression } \\
\text { in terms of } \\
\text { SI base units }\end{array}$ \\
\hline dynamic viscosity & pascal second & $\mathrm{Pa} \cdot \mathrm{s}$ & $\mathrm{m}^{-1} \cdot \mathrm{kg} \cdot \mathrm{s}^{-1}$ \\
\hline noment of force & newton meter & $N \cdot m$ & $\mathrm{~m}^{2} \cdot \mathrm{kg} \cdot \mathrm{s}^{-2}$ \\
\hline surface tension & newton per meter & $\mathrm{N} / \mathrm{m}$ & $\mathrm{kg} \cdot \mathrm{s}^{-2}$ \\
\hline $\begin{array}{l}\text { Dower density, heat flux density, } \\
\text { irradiance }\end{array}$ & watt per square meter & $\mathrm{W} / \mathrm{m}^{2}$ & $\mathrm{~kg} \cdot \mathrm{s}^{-3}$ \\
\hline neat capacity, entropy & joule per kelvin & $\mathrm{J} / \mathrm{K}$ & $\mathrm{m}^{2} \cdot \mathrm{kg} \cdot \mathrm{s}^{-2} \cdot \mathrm{K}^{-1}$ \\
\hline $\begin{array}{l}\text { pecific heat capacity, } \\
\text { specific entropy }\end{array}$ & joule per kilogram kelvin & $\mathrm{J} /(\mathrm{kg} \cdot \mathrm{K})$ & $\mathrm{m}^{2} \cdot \mathrm{s}^{-2} \cdot \mathrm{K}^{-1}$ \\
\hline specific energy & joule per kilogram & $\mathrm{J} / \mathrm{kg}$ & $\mathrm{m}^{2} \cdot \mathrm{s}^{-2}$ \\
\hline hermal conductivity & watt per meter kelvin & $\mathrm{W} /(\mathrm{m} \cdot \mathrm{K})$ & $\mathrm{m} \cdot \mathrm{kg} \cdot \mathrm{s}^{-3} \cdot \mathrm{K}^{-1}$ \\
\hline energy density & joule per cubic meter & $\mathrm{J} / \mathrm{m}^{3}$ & $\mathrm{~m}^{-1} \cdot \mathrm{kg} \cdot \mathrm{s}^{-2}$ \\
\hline electric field strength & volt per meter & $\mathrm{V} / \mathrm{m}$ & $\mathrm{m} \cdot \mathrm{kg} \cdot \mathrm{s}^{-3} \cdot \mathrm{A}^{-1}$ \\
\hline electric charge density & coulomb per cubic meter & $\mathrm{c} / \mathrm{m}^{3}$ & $m^{3} \cdot s \cdot A$ \\
\hline electric flux density & coulomb per square meter & $\mathrm{C} / \mathrm{m}^{2}$ & $m^{-2} \cdot s \cdot A$ \\
\hline Dermittivity & farad per meter & $\mathrm{F} / \mathrm{m}$ & $\mathrm{m}^{-3} \cdot \mathrm{kg}^{-1} \cdot \mathrm{s}^{4} \cdot \mathrm{A}^{2}$ \\
\hline Dermeability & henry per meter & $\mathrm{H} / \mathrm{m}$ & $\mathrm{m} \cdot \mathrm{kg} \cdot \mathrm{s}^{-2} \cdot \mathrm{A}^{-2}$ \\
\hline nolar energy & joule per mole & $\mathrm{J} / \mathrm{mol}$ & $\mathrm{m}^{2} \cdot \mathrm{kg} \cdot \mathrm{s}^{-2} \cdot \mathrm{mol}^{-1}$ \\
\hline olar entropy, molar heat capacity & joule per mole kelvin & $\mathrm{J} /(\mathrm{mol} \cdot \mathrm{K})$ & $\mathrm{m}^{2} \cdot \mathrm{kg} \cdot \mathrm{s}^{-2} \cdot \mathrm{K}^{-1} \cdot \mathrm{mol}$ \\
\hline exposure ( $x$ and $\gamma$ rays) & coulomb per kilogram & $\mathrm{C} / \mathrm{kg}$ & $\mathrm{kg}^{-1} \cdot \mathrm{s} \cdot \mathrm{A}$ \\
\hline absorbed dose rate & gray per second & Gy/s & $m^{2} \cdot s^{-3}$ \\
\hline
\end{tabular}


TABLE 5. SI prefixes

\begin{tabular}{|c|c|c|c|c|c|}
\hline \multirow{2}{*}{$\frac{\text { Factor }}{10^{18}}$} & \multicolumn{2}{|c|}{ Prefix Symbol } & \multirow{2}{*}{$\frac{\text { Factor }}{10^{-1}}$} & \multicolumn{2}{|c|}{ Prefix Symbol } \\
\hline & exa & $E$ & & deci & $\mathrm{d}$ \\
\hline $10^{15}$ & peta & $P$ & $10^{-2}$ & centi & $\mathrm{c}$ \\
\hline $10^{12}$ & tera & $\mathrm{T}$ & $10^{-3}$ & milli & $m$ \\
\hline $10^{9}$ & giga & $G$ & $10^{-6}$ & micro & $\mu$ \\
\hline $10^{6}$ & mega & $M$ & $10^{-9}$ & nano & $\mathrm{n}$ \\
\hline $10^{3}$ & kilo & k & $10^{-12}$ & pico & $p$ \\
\hline $10^{2}$ & hecto & $\mathrm{h}$ & $10^{-15}$ & femto & $f$ \\
\hline $10^{3}$ & deka & $\mathrm{da}$ & $10^{-18}$ & atto & $a$ \\
\hline
\end{tabular}

TABLE 6. Units in use with the International System

\begin{tabular}{|c|c|c|c|}
\hline Name & Symbol & 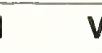 & Jalue in SI Unit \\
\hline minute & $\min$ & $1 \mathrm{~min}$ & $=60 \mathrm{~s}$ \\
\hline hour & $\mathrm{h}$ & $1 \mathrm{~h}$ & $=60 \mathrm{~min}=3600 \mathrm{~s}$ \\
\hline day & d & $1 \mathrm{~d}$ & $=24 \mathrm{~h}=86400 \mathrm{~s}$ \\
\hline degree & $\circ$ & $1^{\circ}$ & $=(\pi / 180) \mathrm{rad}$ \\
\hline minute & ' & $1^{\prime}$ & $=(1 / 60)^{\circ}=(\pi / 10800) \mathrm{rad}$ \\
\hline second & $"$ & $1^{\prime \prime}$ & $=(1 / 60)^{\prime}=(\pi / 648000) \mathrm{rad}$ \\
\hline liter & $L^{*}$ & $1 \mathrm{~L}$ & $=1 \mathrm{dm}^{3}=10^{-3} \mathrm{~m}^{3}$ \\
\hline metric ton & $\mathrm{t}$ & $1 \mathrm{t}$ & $=10^{3} \mathrm{~kg}$ \\
\hline hectare & ha & 1 ha & $=10^{4} \mathrm{~m}^{2}$ \\
\hline
\end{tabular}

TABLE 7. Examples of conversion factors from non-SI units to SI

\begin{tabular}{|c|c|c|c|}
\hline Quantity & Name of Unit & $\begin{array}{c}\text { Symbol } \\
\text { for } \\
\text { Unit }\end{array}$ & $\begin{array}{c}\text { Definition in } \\
\text { SI Units }\end{array}$ \\
\hline length & inch & in & $2.54 \times 10^{-2} \mathrm{~m}$ \\
\hline length & nautical mile* & $\mathrm{nmi}$ & $1852 \mathrm{~m}$ \\
\hline length & angstrom * & $\check{\AA}$ & $10^{-10} \mathrm{~m}$ \\
\hline velocity & knot $^{\star}$ & $\mathrm{kn}$ & $(1852 / 3600) \mathrm{m} / \mathrm{s}$ \\
\hline cross section & barn * & $b$ & $10^{-28} \mathrm{~m}^{2}$ \\
\hline acceleration & $\mathrm{gal}^{*}$ & Gal & $10^{-2} \mathrm{~m} / \mathrm{s}^{2}$ \\
\hline mass & pound (avoirdupois) & $\mathrm{Ib}$ & $0.45359237 \mathrm{~kg}$ \\
\hline force & kilogram-force & kgf & $9.80665 \mathrm{~N}$ \\
\hline pressure & $\begin{array}{l}\text { millimeter of } \\
\text { mercury at } 0^{\circ} \mathrm{C}\end{array}$ & $\mathrm{mmHg}$ & 133.322 Pa† \\
\hline pressure & atmosphere & atm & $101325 \mathrm{~Pa}$ \\
\hline pressure & torr & Torr & $(101325 / 760) \mathrm{Pa}$ \\
\hline pressure & bar $^{\star}$ & bar & $10^{5} \mathrm{~Pa}$ \\
\hline stress & pound-force per sq in & $\mathrm{lbf} / \mathrm{in}^{2}$ & 6894.757 Pat \\
\hline energy & British thermal unit (Int. Table) & Btu & $1055.056 \mathrm{Jt}$ \\
\hline energy & kilowatt hour & kWh & $3.6 \times 10^{6} \mathrm{~J}$ \\
\hline energy & calorie (thermochemical) & cal & $4.184 \mathrm{~J}$ \\
\hline activity (of a radionuclide) & curie $^{\star}$ & $\mathrm{Ci}$ & $3.7 \times 10^{10} \mathrm{~Bq}$ \\
\hline exposure (x or $\gamma$ rays) & roentgen * & $\mathrm{R}$ & $2.58 \times 10^{-4} \mathrm{C} \cdot \mathrm{kg}^{-1}$ \\
\hline absorbed dose & $\operatorname{rad}^{*}$ & rd & $1 \times 10^{-2} \mathrm{~Gy}$ \\
\hline dose equivalent & rem $^{*}$ & rem & $1 \times 10^{-2} \mathrm{~Sv}$ \\
\hline
\end{tabular}




\section{CAPITALS}

Units: When written in full, the names of all units start with a lowercase letter, except at the beginning of a sentence or in capitalized material such as a title. Note that in degree Celsius the unit "degree" is lowercase but the modifier "Celsius" is capitalized. The "degree centigrade" is obsolete.

Symbols: Unit symbols are written with lowercase letters except that (1) the first letter is uppercase when the name of the unit is derived from the name of a person and (2) the symbol for liter is capital L.

Prefixes: The symbols for numerical prefixes for $\operatorname{exa}(E)$, peta $(P)$, tera $(T)$, giga $(G)$, and mega $(M)$ are written with yppercase letters, all others with lowercase letters. All prefixes are written in lowercase letters when written out in full, except where the entire unit name is written in uppercase letters.

\section{PLURALS}

a. When written in full, the names of units are made plural when appropriate. Fractions both common and decimal are always singular.

b. Symbols for units are the same in singular and plural (no " $\mathrm{s}$ " is ever added to indicate a plural).

\section{PERIODS}

A period is NOT used after a symbol, except at the end of a sentence.

\section{THE DECIMAL MARKER}

The dot (point) is used as the decimal marker and is placed on the line. In numbers less than one, a zero must be written before the decimal point.

\section{GROUPING OF DIGITS}

a. Digits should be separated into groups of three, counting from the decimal marker. The comma should not be used. Instead, a space is left to avoid confusion, since many countries use a comma for the decimal marker.

b. In numbers of four digits, the space is not recommended, unless four-digit numbers are grouped in a column with numbers of five digits or more.

\section{SPACING}

a. In symbols or names for units that have prefixes, no space is left between letters making up the symbol or the name.

b. When a symbol follows a number to which rafers, a space must be left between the number and the symbol (except for degree, minute, and second of angle).

\section{COMPOUND UNITS}

In the symbol for a compound unit that is formed by the multiplication of two or more units, a centered dot is used. For example, $\mathrm{N} \cdot \mathrm{m}$.

In the name of such a unit, a space is recommended (or a hyphen is permissible) but never a centered dot. For example, newton meter or newton-meter.

\section{APPENDIX 3 \\ Quotation from the American National Standard for Metric Practice, Z210.1-1976}

3.4.1.1 The principal departure of SI from the gravimetric system of metric engineering units is the use of explicitly distinct units for mass and force. In SI, the name kilogram is restricted to the unit of mass, and the kilogram-force (from which the suffix force was in practice often erroneously dropped) should not be used. In its place, the SI unit of force, the newton, is used. Likewise, the newton rather than the kilogram-force is used to form derived units which include force, for example, pressure or stress $\left(\mathrm{N} / \mathrm{m}^{2}=\mathrm{Pa}\right)$, energy $(\mathrm{N} \cdot \mathrm{m}=\mathrm{J})$, and power $(\mathrm{N} \cdot \mathrm{m} / \mathrm{s}=\mathrm{W})$.

3.4.1.2 Considerable confusion exists in the use of the term weight as a quantity to mean either force or mass. In commercial and everyday use, the term weight nearly always means mass; thus, when one speaks of a person's weight, the quantity referred to is mass. This nontechnical use of the term weight in everyday life will probably persist. In science and technology, the term weight of a body has usually meant the force that, if applied to the body, would give it an acceleration equal to the local acceleration of free fall. The adjective "local" in the phrase "local acceleration of free fall" has usually meant a location on the surface of the earth; in this context the "local acceleration of free fall" has the symbol g (commonly referred to as "acceleration of gravity") with observed values of $g$ differing by over 0.5 percent at various points on the earth's surface. The use of force of gravity (mass times acceleration of gravity) instead of weight with this meaning is recommended. Because of the dual use of the term weight as a quantity, this term should be avoided in technical practice except under circumstances in which its meaning is completely clear. When the term is used, it is important to know whether mass or force is intended and to use SI units properly as described in 3.4.1.1, by using kilograms for mass or newtons for force. 
-

0

- 